BRIEF REPORT

\title{
Bidi and cigarette smoking and risk of acute myocardial infarction among males in urban India
}

\author{
T Rastogi, P Jha, K S Reddy, D Prabhakaran, D Spiegelman, M J Stampfer, W C Willett, A Ascherio
}

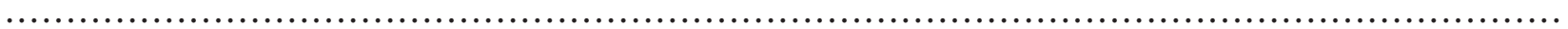

Tobacco Control 2005;14:356-358. doi: 10.1136/tc.2005.011965

\begin{abstract}
Death from myocardial infarction (MI) in India is exacerbated by smoking of bidis or cigarettes. Smoking among 309 men with incident MI was compared to 618 age matched controls; $56 \%$ of the individuals with $\mathrm{Ml}$ and $26 \%$ of controls were current smokers. Current smokers had a relative risk of 4.7 ( $95 \%$ confidence interval (CI) 3.2 to 6.9) compared to never smokers. Relative risks for smoking more than 10 cigarettes or 10 bidis daily were $9.1(95 \% \mathrm{Cl} 4.7$ to 17.7$)$ and 8.1 $195 \% \mathrm{Cl} 4.3$ to 15.3), respectively. It is estimated that smoking may cause $53 \%(95 \% \mathrm{Cl} 47 \%$ to $64 \%$ ) of Mls among urban males in India.
\end{abstract}

M yocardial infarction (MI) is a leading cause of mortality and disability of adults in urban and rural India, and occurs at a younger age than in western populations. ${ }^{1}$ For example, about $30 \%$ of all estimated MI mortality occurs at ages 45-59 years in India, versus only 14\% in high income countries. Male smoking of cigarettes or, more commonly, bidis-small unfiltered cigarettes hand rolled in a temburni leaf-is well established in India and has been recently documented as a major cause of death among Indian men, ${ }^{2}$ with much of this resulting from vascular and respiratory disease. ${ }^{2}$ Smoking of cigarettes and bidis has been associated with a twofold risk for fatal MI in India. ${ }^{2}$

The risks of smoking for non-fatal MI are less well established in India. The large hospital based "Interheart" case-control study, which included some 2171 patients from "South Asia", found a threefold relative risk of MI for smoking, with a population attributable risk of $37 \%{ }^{4}$ We know of only one study in India (based at one referral hospital) that examined the risk of smoking bidis or cigarettes and non-fatal MI. ${ }^{5}$ The risks of smoking for nonfatal MI were among a younger population than that seen in the Interheart or other western studies. ${ }^{6}$ Indeed, even within largely western populations, the international World Health Organization MONICA (multinational monitoring of trends and determinants in cardiovascular disease) project recently reported a nearly fivefold elevation in risk for non-fatal MI associated with current smoking in younger men. ${ }^{7}$

Given the younger age of onset of cardiovascular disease in Indians and the unique patterns of bidi use, it is critical that risk for non-fatal MI be assessed in this population. We report here a case-control study of acute incident MI from eight hospitals in two cities in the north and south of India, and the risks associated with both cigarette and bidi smoking.

\section{METHODS}

Details of case and control selection, exclusion criteria, measurements made, and interview procedures have been published previously. ${ }^{8}$ Ethics approval was received from all participating hospitals and from the Harvard School of Public Health. In brief, eligible cases were men aged 21-74 years hospitalised with incident acute MI among eight urban hospitals in Bangalore and New Delhi between 1999 and 2000 (female smoking is uncommon in India (Jha P, personal communication, 2005) and we do not report here on the results of the 41 women with MI interviewed). Definite diagnosis of MI was based on clinical examination, electrocardiogram, and cardiac enzymes. A total of 363 men met eligibility criteria, and 309 were included in the study; 54 eligible cases were excluded for the following reasons: fatal incident MI patients $(\mathrm{n}=21)$, discharged before interview could take place $(\mathrm{n}=18)$, too sick to be interviewed $(\mathrm{n}=9)$, and not willing to be interviewed $(\mathrm{n}=6)$. For each case, two controls matched by age (within five years) and hospital were obtained from non-cardiac outpatient clinics or inpatient wards. Controls comprised relatively healthy men with minor ailments or conditions. We identified 623 eligible controls, five of whom refused participation. Subjects were interviewed in person, and asked to report the number of bidis and/or cigarettes smoked per day. Anthropometric measures were also obtained. Analyses of cigarette and bidi smoking and risk of MI used standard conditional logistic regression, first controlling for age and hospital, and then, in addition, other potential risk factors demonstrated in previous studies. ${ }^{4}{ }^{8}$ These risk factors include body mass index $\left(<21 \mathrm{~kg} / \mathrm{m}^{2}, \geqslant 21-23, \geqslant 23-26, \geqslant 26\right)$, waist to hip ratio $(\leqslant 0.91,>0.91-0.95,>0.95-0.98$, $>0.98$ ), physical activity (none, $<155$ met-min per day of exercise, $\geqslant 155$ ), history of hypertension (yes, no), history of diabetes (yes, no), history of high cholesterol (yes, no), family history of coronary heart disease (yes, no), alcohol intake (no intake, any intake), education (none, primary school, middle, secondary, higher secondary, college, graduate/professional), household income $(<3000$ rupees per month, 3000-6000, 6000-10 000, > 10000$)$, and being Hindu (yes, no). ${ }^{8}$ Population attributable risk was calculated using the prevalence of smoking in the adult (30+) male urban population (prevalence $31 \%)^{9}$ and the relative risk observed with current smoking in our study (population attributable risk $=$ [prevalence smoking $\left.\left(\mathrm{RR}_{\text {smoking }}-1\right)\right]$ / $\left.\left[\operatorname{prev}_{\text {smoking }}\left(\operatorname{RR}_{\text {smoking }}-1\right)+1\right]\right)$.

\section{RESULTS}

Fifty six per cent of the 309 male cases and $26 \%$ of the 618 male controls currently smoked either bidis or cigarettes. Overlap of bidi and cigarette use was low; only $16 \%$ of current bidi smokers used cigarettes and $14 \%$ of current cigarette smokers used bidis. Compared to never smokers, current smokers were younger, had lower body mass indexes and physical activity levels, and higher levels of alcohol intake (data not shown).

Current and former smokers had significantly increased risk for MI, with current smokers having a higher risk than former smokers (table 1). 
Table 1 Relative risk (RR) of acute incident myocardial infarction (MI) among males according to smoking history

\begin{tabular}{lcllll}
\hline $\begin{array}{l}\text { Smoking } \\
\text { status* }\end{array}$ & $\begin{array}{l}\text { Cases } \\
\mathbf{n = 3 0 9}\end{array}$ & $\begin{array}{l}\text { Controls } \\
\mathbf{n = 6 1 8}\end{array}$ & $\begin{array}{l}\text { Age and hospital } \\
\text { adjusted RR }(\mathbf{9 5 \%} \mathrm{Cl})\end{array}$ & $\begin{array}{l}\text { Multivariate } \\
\text { adjusted RR } \\
(\mathbf{9 5 \%} \mathrm{Cl})\end{array}$ & $\begin{array}{l}\text { Number of smoking } \\
\text { associated Ml casest (\%) }\end{array}$ \\
\hline Never & 82 & 359 & 1.0 & 1.0 & - \\
Ever & 220 & 240 & $4.0(3.0$ to 5.4$)$ & $3.9(2.8$ to 5.6$)$ & $163(74 \%)$ \\
Former & 47 & 77 & $2.7(1.7$ to 4.1$)$ & $2.6(1.6$ to 4.3$)$ & $29(62 \%)$ \\
Current & 173 & 163 & $4.6(3.4$ to 6.4$)$ & $4.7(3.2$ to 6.9) & $136(79 \%)$ \\
\hline
\end{tabular}

*Never smokers (reference group) does not include cigarette smokers, bidi smokers, or users of other forms of tobacco ( $n=7$ cases and $n=19$ controls used other forms of tobacco only). Ever smokers include former and current cigarette or bidi smokers. Current smokers include current smokers of cigarettes or bidis. $\dagger$ Smoking associated number of $\mathrm{Ml}$ cases calculated as ( $1-1 /$ risk ratio) $\times$ number of cases who smoked in that group.

In comparison to never smokers, current smokers had an age adjusted relative risk (RR) of 4.6 (95\% confidence interval (CI) 3.4 to 6.4). This risk changed little with multivariate adjustment. In multivariate analysis of bidi smoking (table 2), persons consuming more than 10 bidis per day (median 20 bidis/day) had an RR of 9.1 (95\% CI 4.7 to 17.7; $\mathrm{p}$ for trend <0.0001). In multivariate analysis of cigarette smoking, persons consuming more than 10 cigarettes per day (median 15 cigarettes/day) had an RR of 7.3 (95\% CI 3.9 to 13.8; p for trend < 0.0001 ) in comparison to never smokers. After excluding men who consumed both cigarettes and bidis $(\mathrm{n}=27)$, risk estimates for bidi smoking did not change substantially, while risk in the higher category of cigarette smoking slightly increased though with wider confidence intervals. No significant interaction was found between bidi or cigarette smoking and other coronary risk factors, although the statistical power to detect small interactions was limited.

\section{DISCUSSION}

Our fourfold increased risk associated with current smoking for non-fatal MI is consistent with findings from the Interheart study, where a threefold elevation in risk was observed. ${ }^{4}$ Two western studies have already documented that the RRs for smoking are more extreme (even at lower absolute risks) at younger ages. ${ }^{5}$ The observed risk for nonfatal MI are about double that shown for fatal MI in India. ${ }^{2}$ The higher RRs for non-fatal MI might be accounted for partly by higher quitting rates before death. Misclassification of smoking in fatal MI studies would tend to attenuate risk estimates. The true estimate of risk might be accurately shown in non-fatal MI studies where persons with no prior history of any cardiovascular disease are included. Our exsmoking prevalence of $15 \%$ among MI cases and 13\% among controls is significantly higher than that reported in the general population. ${ }^{3}{ }^{10}$ This implies that the early detection of MI risk among cases or clinical attention and access to hospital care among controls might lead to higher quit rates. This would tend to lower our observed risk ratios.

Notably, our results are remarkably consistent with an earlier retrospective study of 300 cases and 300 controls (93\% of which were males) from one hospital in India. ${ }^{5}$ An unadjusted pooled Mantel-Haenszel RRs for MI with smoking for the two studies among current smokers is 3.7 (95\% CI 2.9 to 4.6 , test for heterogeneity $0.13, \mathrm{p}=0.7$ ).

The observed current smoking prevalence among our controls of $29 \%$ is about the same as that seen in urban males in India in two surveys of 100000 households, ${ }^{9}$ and of one million households (Jha P, personal communication, 2005) Thus, we estimate that smoking causes 53\% (95\% CI $47 \%$ to $64 \%$ ) of MIs among urban males in India (using a male adult smoking prevalence of $31 \%$ ).

The large RRs and a dose-response relationship with increased bidi or cigarette smoking, comparable to that seen in an earlier study, ${ }^{5}$ support a causal relation. Potential sources of bias in our study are not likely to have greatly affected the observed risks. There was little difference in risks between different sources of controls (clinics or inpatient wards; data not shown), suggesting that selection bias was minimal. Although health conscious individuals may have been more likely to participate in the study, overall participation rates were high. Controls were slightly more educated but had lower incomes than cases. However, controlling for recorded socioeconomic factors did not alter our findings significantly. Differential recall of smoking history was likely to be modest because smoking is recalled relatively easily. Our study provides risk estimates for tobacco smoking in urban India among males. Rural areas have

Table 2 Relative risk (RR) of acute incident myocardial infarction (MI) in males according to amount of current cigarette or bidi smoking

\begin{tabular}{|c|c|c|c|c|c|}
\hline Smoking status* & $\begin{array}{l}\text { Median (cigarette } \\
\text { or bidi per day) }\end{array}$ & $\begin{array}{l}\text { Cases } \\
\text { (n)t }\end{array}$ & $\begin{array}{l}\text { Controls } \\
\text { (n)t }\end{array}$ & $\begin{array}{l}\text { Age and hospital } \\
\text { adjusted RR }(95 \% \mathrm{Cl})\end{array}$ & $\begin{array}{l}\text { Multivariate RR } \\
(95 \% \mathrm{Cl})\end{array}$ \\
\hline $\begin{array}{l}\text { Never smokers } \\
\text { Bidi smokers: }\end{array}$ & 0 & 82 & 359 & 1.0 & 1.0 \\
\hline $\begin{array}{l}<10 \text { per day } \\
>10 \text { per day }\end{array}$ & $\begin{array}{r}4 \\
20\end{array}$ & $\begin{array}{l}16 \\
71\end{array}$ & $\begin{array}{l}39 \\
39\end{array}$ & $\begin{array}{l}1.9(1.0 \text { to } 3.6) \\
8.8(5.2 \text { to } 14.8)\end{array}$ & $\begin{array}{l}2.0(0.9 \text { to } 4.4) \\
8.1(4.3 \text { to } 15.3)\end{array}$ \\
\hline $\begin{array}{l}\text { Test for trend: } p \text { value } \\
\text { Cigarette smokers }\end{array}$ & & & & $<0.0001$ & $<0.0001$ \\
\hline $\begin{array}{l}<10 \text { per day } \\
>10 \text { per day } \\
\text { Test for trend: } p \text { value }\end{array}$ & $\begin{array}{r}3 \\
15\end{array}$ & $\begin{array}{l}44 \\
61\end{array}$ & $\begin{array}{l}65 \\
28\end{array}$ & $\begin{array}{l}3.1(1.9 \text { to } 4.9) \\
9.4(5.4 \text { to } 16.2) \\
<0.0001\end{array}$ & $\begin{array}{l}3.2(1.8 \text { to } 5.7) \\
9.1(4.7 \text { to } 17.7) \\
<0.0001\end{array}$ \\
\hline
\end{tabular}

*Never smokers does not include bidi smokers, cigarette smokers, or users of other forms of tobacco. Current smokers of bidis and cigarettes are presented.

†Approximately $n=19$ cases and $n=8$ controls smoked both cigarettes and bidis and are represented in both groups. 


\section{What this paper adds}

This study adds evidence on the adverse effect of tobacco smoking on the risk for non-fatal myocardial infarction (MI) in men in urban India. Importantly, we provide evidence on the risk associated with bidi smoking. First, we observed an over fourfold increase in risk associated with current smoking (bidi or cigarette) in this population compared to never smokers. More specifically, men smoking 10 or more bidis per day were over seven times more likely to have an MI than never smokers. Finally, we estimate that nearly $60 \%$ of Mls in males in urban India can be attributed to tobacco smoking.

different disease patterns, access to care, and differences in smoking patterns. ${ }^{2} 9$ The ongoing Registrar General of India's one million death study will provide further data on smoking hazards in different regions including rural India and among different background disease rates. ${ }^{11}$

The implication for tobacco control is clear: that reduced smoking will reduce the leading cause of adult death in India. Tobacco prevention in India is beginning to be addressed at the national level with legislation that bans advertising, sponsorship of sports, and cultural events by tobacco companies, smoking in public places, and sale of tobacco products to people younger than 18 years of age. ${ }^{12}$

Our results add additional impetus in particular to cessation: some 70-80 million males over the age of 30 smoke, ${ }^{10}$ with vascular disease, tuberculosis and cancers being the major cause of premature mortality and disability among these men. Avoidance of tobacco related disease over the next few decades will require current smokers to quit, with the greatest benefits if quitting occurs before the onset of disease. ${ }^{13}$

\section{ACKNOWLEDGEMENTS}

We thank staff at the eight hospitals in Bangalore and New Delhi, noted in an earlier publication, for helping make the study possible. The study was supported in part by the Unilever Corporation, and, in part, by a tobacco research grant ( $\mathrm{P}$ Jha) from the Fogarty International Center, US National Institutes of Health (R0I TW05991-01). However, the sponsors of the study had no role in the study design, data collection, data analysis, data interpretation, or writing of the report.

\section{Authors' affiliations}

T Rastogi, Department of Nutrition, Harvard School of Public Health, Boston, Massachusetts, USA
P Jha, Public Health Sciences, University of Toronto, Toronto, Canada K S Reddy, D Prabhakaran, All India Institute of Medical Sciences, New Delhi, India

D Spiegelman, Departments of Biostatistics and Epidemiology, Harvard School of Public Health

M J Stampfer, W C Willett, A Ascherio, Departments of Nutrition and Epidemiology, Harvard School of Public Health

Competing interests: none declared

Study design and data collection were done by TR, AA, WCW, KSR, DP, DS. Data analysis and interpretation were done by TR, PJ, AA, WCW, MJS, DS. Manuscript preparation was done by TR and PJ with critical feedback on the manuscript provided by AA, WCW, MJS, KSR, DP, DS.

Correspondence to: Dr Tanuja Rastogi, National Cancer Institute, Division of Cancer Epidemiology \& Genetics, Nutritional Epidemiology Branch, 6120 Executive Blvd, EPS 320, Rockville, MD 20852, USA; TRASTOGI@post.harvard.edu

Received 24 March 2005

Accepted 20 July 2005

\section{REFERENCES}

1 World Health Organization. Reducing risks: promoting health life: world health report 2002. Geneva: WHO, 2005.

2 Gajalakshmi V, Peto R, Kanaka TS, Jha P. Smoking and mortality from tuberculosis and other diseases in India: retrospective study of 43000 adult male deaths and 35000 controls. Lancet 2003;362:507-15.

3 Gupta PC, Mehta HC. Cohort study of all-cause mortality among tobacco users in Mumbai, India. Bull World Health Organ 2000;78:877-83.

4 Yusuf S, Hawken S, Ounpuu S, et al. Effect of potentially modifiable risk factors associated with myocardial infarction in 52 countries (the INTERHEART study): case-control study. Lancet 2004;364:937-52.

5 Pais P, Fay MP, Yusuf S. Increased risk of acute myocardial infarction associated with beedi and cigarette smoking in Indians: final report on tobacco risks from a case-control study. Indian Heart J 2001;53:731-5.

6 Parish S, Collins R, Peto R, et al. Cigarette smoking, tar yields, and non-fatal myocardial infarction: 14,000 cases and 32,000 controls in the United Kingdom. The international studies of infarct survival (ISIS) collaborators. BMJ 1995;31 1:471-7.

7 Mahonen MS, McElduff P, Dobson AJ, et al. Current smoking and the risk of non-fatal myocardial infarction in the WHO MONICA project populations. Tobacco Control 2004; 13:244-50.

8 Rastogi T, Reddy KS, Vaz M, et al. Diet and risk of ischemic heart disease in India. Am J Clin Nutr 2004;79:582-92.

9 Rani M, Bonu S, Jha P, et al. Tobacco use in India: prevalence and predictors of smoking and chewing in a national cross sectional household survey. Tobacco Control 2003; 12:e4.

10 Jha P, Ranson MK, Nguyen SN, et al. Estimates of global and regional smoking prevalence in 1995, by age and sex. Am J Public Health 2002;92:1002-6

11 Jha P, Sinha SK, Gajalakshmi V, et al. Options for implementing verbal autopsy instruments and epidemiologic relevant questions into the sample registration system. Proceedings of all-India workshop on civil registration and causes of death. New Delhi, 2005.

12 Reddy KS, Gupta PC. Report on tobacco control in India, Ministry of Health and Family Welfare, Government of India, 2005.

13 Doll R, Peto R, Boreham J, et al. Mortality in relation to smoking: 50 years' observations on male British doctors. BMJ 2004;328:1519. 